\title{
Prototipe Aplikasi SiMaRCo (System Material Request Control) dalam Mendukung Pengendalian Persediaan Pada PT. Angkasa Pura Solusi
}

\author{
Oleh Soleh ${ }^{1}$, Muhamad Wahyudin ${ }^{2}$ dan Anggit Cahya Laksana ${ }^{3}$ \\ ${ }_{1,2,3}$ Sistem Informasi, Universitas Raharja, JL. Jendral Sudirman No.40 \\ Cikokol, Tangerang, Indonesia, 15117 \\ E-mail : oleh.soleh@raharja.info ${ }^{1}$; wahyudin@ raharja.info²; anggit.cahya@ raharja.info ${ }^{3}$ \\ Correspondence: Oleh Soleh (oleh.soleh@raharja,info) \\ Received: 010821 - Revised: 040821 - Accepted: 040821 - Published: 261021
}

\begin{abstract}
Abstrak. Keberhasilan suatu perusahaan bisa dimulai dari baiknya sistem permintaan peralatan yang ada diperusahaan tersebut. Pengendalian permintaan peralatan perlu diperhatikan oleh perusahaan karena sangat menentukan kelancaran kegiatan operasional dalam mencapai keuntungan sebesar-besarnya dengan biaya seminimal mungkin. Saat ini sistem permintaan peralatan yang berjalan pada PT. Angkasa Pura Solusi kurang optimal, karena perhitungan anggaran nilai kontrak dengan biaya permintaan peralatan yang diajukan, pelaporan peralatan terpakai, dan laporan permintaan peralatan yang dibutuhkan masih menggunakan Ms. Excel. Hal ini mengakibatkan waktu yang tidak efektif serta sering terjadi kesalahan permintaan peralatan yang diperlukan di area dan mengakibatkan pengeluaran biaya operasional yang meningkat. Oleh karena itu, penelitian ini mengusulkan sistem permintaan peralatan berbasis Android agar terciptanya sistem yang lebih cepat, tepat dan akurat. Adapun metode perancangan sistem dengan menggunakan Prototype, karena metode perancangan ini sangat penting dilakukan sebelum membangun sistem permintaan peralatan menjadi lebih efektif dan efisien.
\end{abstract}

Kata kunci: Apliksi, Permintaan, Persediaan, Pengendalian

Citation Format: Soleh,O., Wahyudin, M., dan Laksana, A.C., (2021). Prototipe Aplikasi SiMaRCo (System Material Request Control) dalam Mendukung Pengendalian Persediaan Pada PT. Angkasa Pura Solusi. Prosiding Seminar Nasional Abdimas Ma Chung (SENAM), 2021, 91-100. 


\section{PENDAHULUAN}

Teknologi dan cara kerja manusia mengalami perkembangan yang sangat pesat sekali. Dengan adanya teknologi pekerjaan yang dulunya dilakukan dengan cara manual dan memerlukan banyak waktu dalam menyelesaikannya, sekarang dapat dilakukan dengan bantuan teknologi yang canggih dan tidak memerlukan waktu yang terlalu lama dalam menyelesaikannya.

PT. Angkasa Pura Solusi merupakan salah satu anak perusahaan PT. Angkasa Pura II (Persero) yang bergerak dalam bidang usaha pelayanan jasa kebandarudaraan, salah satunya di bidang pelayanan jasa Cleaning Service. Sebagai perusahaan yang bergerak dibidang pelayanan jasa kebersihan PT. Angkasa Pura Solusi memiliki banyak peralatan yang digunakan untuk mengelola kebersihan dan perawatan ruang lingkup yang masuk kedalam luasan pekerjaan.

Sistem permintaan peralatan (Material Request) merupakan proses yang kompleks, dengan mempertimbangkan biaya pengeluaran yang tidak melebihi batas biaya yang ditentukan sesuai dengan nilai kontrak pekerjaannya, tetapi sebenarnya dasar-dasarnya sama saja terlepas dari ukuran atau jenis perusahaannya.

Setiap perusahaan pasti menginginkan pendapatan yang lebih besar dari biaya kebutuhan yang dikeluarkan untuk segala kegiatan operasional di dalamnya. Salah satunya pada biaya permintaan peralatan Cleaning Service pada PT. Angkasa Pura Solusi yang sangat berpengaruh terhadap pendapatan. Banyaknya permintaan peralatan yang melebihi biaya pendapatan menjadi penyebab utama turunnya pendapatan yang dihasilkan.

Proses material request yang biasanya dilakukan secara manual tidak lagi menjadi pilihan utama bagi suatu perusahaan. Sistem Informasi adalah alternatif yang paling cocok untuk memberikan data yang sangat akurat dan memiliki tingkat sekuritas yang terjamin.

Data mentah menjadi sebuah informasi yang berguna bagi para pengambil keputusan dalam proses perencanaan, pemantauan dan pengendalian. Pada beberapa bagian perusahaan, pengambilan keputusan dilakukan secara periodik baik mingguan, bulanan atau kuartal dan membutuhkan sekumpulan informasi yang cepat dan tepat untuk membuat keputusan. Dapat dipahami disini bahwa informasi yang dibutuhkan untuk memformulasikan sebuah keputusan yang dapat diidentifikasikan.

Untuk itu diperlukan sistem permintaan peralatan (Material Request) yang terintegrasi dan terkontrol dengan baik agar menjaga marjin pendapatan yang lebih tinggi 
dari biaya operasional yang dikeluarkan dan juga agar informasi mengenai persediaan dalam permintaan peralatan sesuai dan akurat dengan kebutuhan operasional.

Pengelolaan sistem informasi yang cepat, tepat dan akurat akan sangat membantu suatu perusahaan untuk dapat memecahkan berbagai permasalahan yang ada maupun untuk pengambilan keputusan sehingga dapat membantu perusahaan tersebut mencapai target tujuannya, salah satunya adalah PT. Angkasa Pura Solusi yang memiliki sistem Material Request yang masih berjalan manual, maka dengan latar belakang diatas penulis mengambil judul "PROTOTYPE APLIKASI SI-MARCO (SYSTEM MATERIAL REQUEST CONTROL) DALAM MENDUKUNG PENGENDALIAN PERSEDIAAN PADA PT. ANGKASA PURA SOLUSI".

\section{PERMASALAHAN}

Berdasarkan latar belakang diatas dan data hasil observasi yang didapat oleh peneliti dilapangan, masih banyak ditemukan masalah yang terjadi. Seperti banyaknya data permintaan peralatan yang melebihi beban biaya dari nilai kontrak pekerjaan, sehingga mempengaruhi cost pendapatan perusahaan dan laporan peralatan yang digunakan tidak akurat.

Untuk meminimalisir terjadinya over cost pada biaya permintaan peralatan yang mempengaruhi keuntungan pendapatan, dan mempermudah laporan peralatan yang digunakan agar bisa terkontrol dengan baik, maka peneliti ingin merubah sistem permintaan peralatan (Material Request) berbasis android.

Untuk melengkapi laporan penelitian agar tertata rapih dan lebih tersusun maka perlu adanya ruang lingkup penelitian yang bermaksud membatasi masalah yang akan dibahas. Adapun ruang lingkup penelitian meliputi:

Proses pencatatan stok persediaan peralatan ditulis manual dan diinput pada Ms. Excel setiap peralatan yang masuk dan penggunaan peralatan keluar dan dilaporkan kepada atasan terkait. Permintaan peralatan yang dibuat PIC area dilakukan dengan cara melihat stok peralatan yang dibutuhkan untuk membuat permintaan peralatan dengan menggunakan Ms. Excel yang dikirim kepada Staf Logistik Pusat untuk diperiksa kembali biaya permintaannya sebelum diproses permintaan peralatannya.

Laporan profit and loss area dibuat oleh Manajer dan hanya diketahui oleh staf Logistik Pusat, sehingga PIC area tidak dapat mempertimbangkan biaya permintaan peralatan yang diajukan agar tidak melebihi nilai kontrak. 


\section{METODE PELAKSANAAN}

Pada bagian metode diuraikan cara yang digunakan untuk menyelesaikan masalah, tantangan, atau persoalan. Dalam hal ini dapat digunakan satu jenis metode atau kombinasi beberapa jenis metode.

Untuk memperoleh akurasi data yang relevan digunakan metode perancangan sistem melalui beberapa proses, diantaranya :

\section{1) Jenis Penelitian}

Jenis Penelitian ini menggunakan metode penelitian deskriptif, yang berfokus pada penjelasan sistematis tentang fakta yang diperoleh saat penelitian dilakukan. Sanusi (2011:13) mendefinisikan, desain penelitian deskriptif adalah desain penelitian yang disusun dalam rangka memberikan gambaran secara sistematis tentang informasi ilmiah yang berasal dari subjek atau objek penelitian. Karakteristik penelitian deskriptif adalah dilakukan pada kondisi yang alamiah langsung ke sumber data dan peneliti adalah sumber instrumen kunci, data yang terkumpul berbentuk kata-kata atau gambar, sehingga tidak menekankan pada angka.

\section{2) Sumber Data}

Pengumpulan data juga dikategorikan ke dalam sumber-sumber data antara lain:

\section{a) Data Primer}

Merupakan data yang diperoleh langsung dari perusahaan atau data yang terjadi di lapangan yang diperoleh dari wawancara dengan kepala bagian persediaan.

\section{b) Data Sekunder}

Merupakan data yang diperoleh dari perusahaan dalam bentuk yang sudah jadi, seperti: struktur organisasi, laporan stok opname, persediaan, dan laporan penggunaan peralatan.

\section{3) Pengumpulan Data}

Pengumpulan data dilakukan dengan mengamati langsung ke PT. Angkasa Pura Solusi dan wawancara terhadap pihak staf Logistik Pusat untuk mengetahui proses sistem permintaan peralatan (material request) yang berjalan saat ini.

\section{4) Analisis}

Setelah dilakukan pengumpulan data, maka dihasilkan analisis sistem berupa kebutuhan fungsional diantaranya:

a) Fungsi Login: mengelola data user dan password yang dimasukan oleh admin dengan benar dan selanjutnya memilih menu. 
b) Fungsi stok barang: mengelola data jumlah peralatan.

c) Fungsi permintaan barang: membuat pengajuan permintaan peralatan

d) Fungsi laporan keluar masuk barang: mengelola data keluar masuk barang yang terjadi setiap hari pada bulan dan tahun yang telah ditentukan.

e) Fungsi profit and loss: mengetahui laporan cash flow pendapatan dan pengeluaran biaya kebutuhan

f) Fungsi Logout: keluar dari aplikasi kas kecil

\section{5) Perancangan Sistem}

Perancangan sistem usulan digambarkan dengan menggunakan prototyping. Perancangan ini menghasilkan prototipe dari suatu perangkat lunak yang dapat digunakan sebagai perantara pengembang dengan pengguna untuk berinteraksi dalam perancangan sistem informasi. Prototype adalah sebuah versi awal dari perangkat lunak yang digunakan untuk mendemonstrasikan konsep, mencoba berbagai pilihan desain, dan menggali lebih banyak permasalahan dan solusinya (I. Sommerville, 2016). Beberapa manfaat prototyping adalah (D. Purnomo, 2017:54-61):

a) Mewujudkan sistem sesungguhnya dalam sebuah replika sistem yang akan berjalan, menampung masukan dari pengguna untuk kesempurnaan sistem.

b) Pengguna akan lebih siap menerima setiap perubahan sistem yang berkembang sesuai dengan berjalannya prototipe sampai dengan hasil akhir sistem yang dikembangkan.

c) Prototype dapat ditambah maupun dikurangi ketika proses pengembangan sedang berjalan. Kemajuan tahap demi tahap dapat diikuti langsung oleh pengguna.

d) Penghematan sumber daya dan waktu dalam menghasilkan produk yang lebih baik dan tepat guna bagi pengguna.

\section{HASIL DAN PEMBAHASAN}

\section{Rancangan Prototype Aplikasi Si-Marco}

Rancangan prototype Aplikasi Si-MaRCo dibuat untuk mempermudah gambaran dari rancangan aplikasi Si-MaRCo dengan membuat tampilan sesuai kepentingan yang dibutuhkan. 


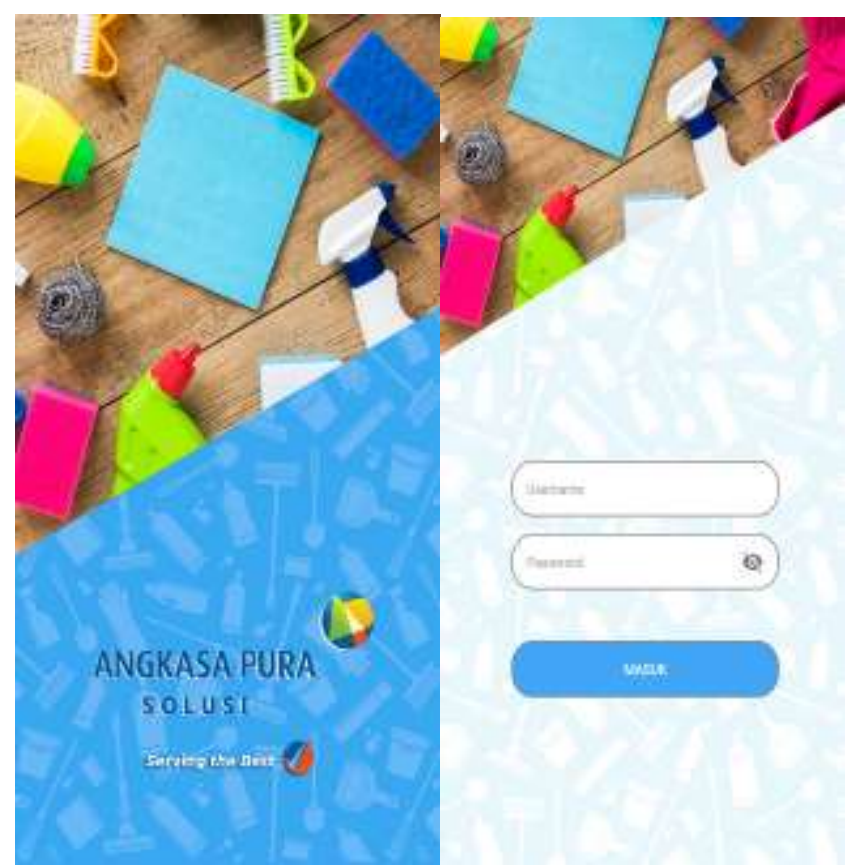

Gambar 1. Rancangan Halaman Login

Tampilan halaman login adalah tampilan untuk admin jika ingin memasuki sistem dengan memasukan username dan password yang merupakan nomor induk karyawan (NIK) dan bisa diubah dengan password yang diinginkan pada halaman profil ubah password .

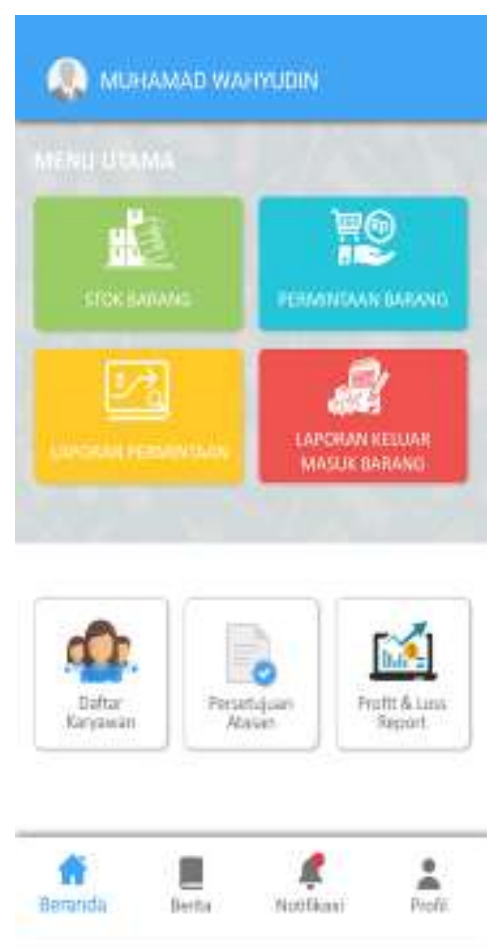

Gambar 2. Tampilan Beranda 
Gambar 2 setelah admin berhasil login akan diarahkan pada tampilan beranda Aplikasi Si-MaRCo untuk memilih menu yang digunakan selanjutnya.

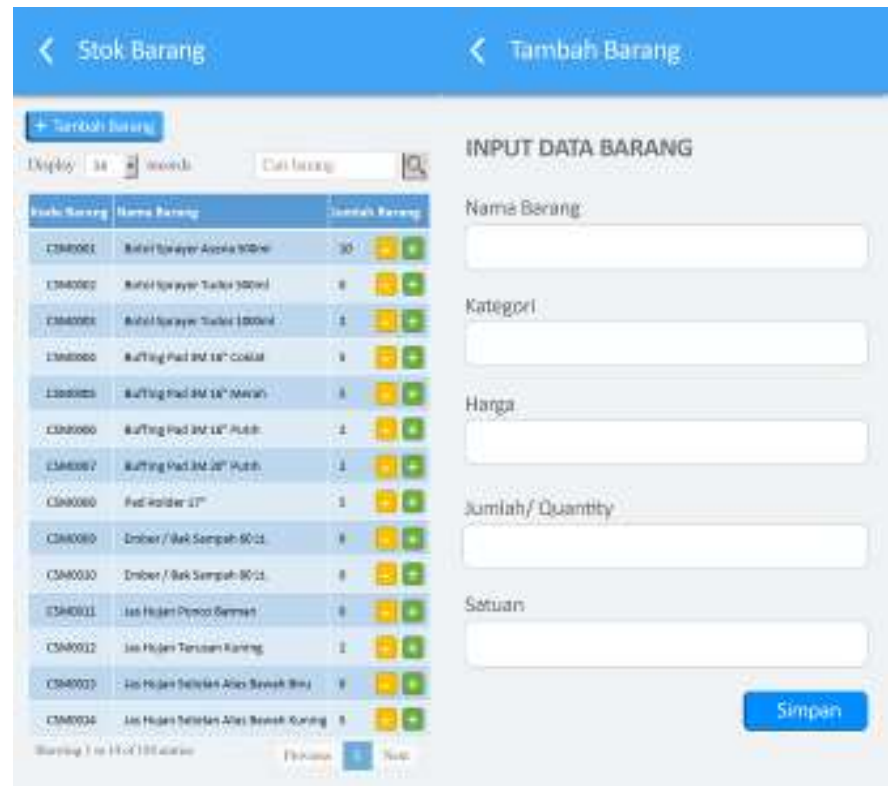

Gambar 3. Tampilan Stok Barang

Gambar 3 merupakan tampilan menu Stok Barang untuk mengelola data stok barang/ peralatan, menambahkan peralatan masuk dan peralatan keluar.

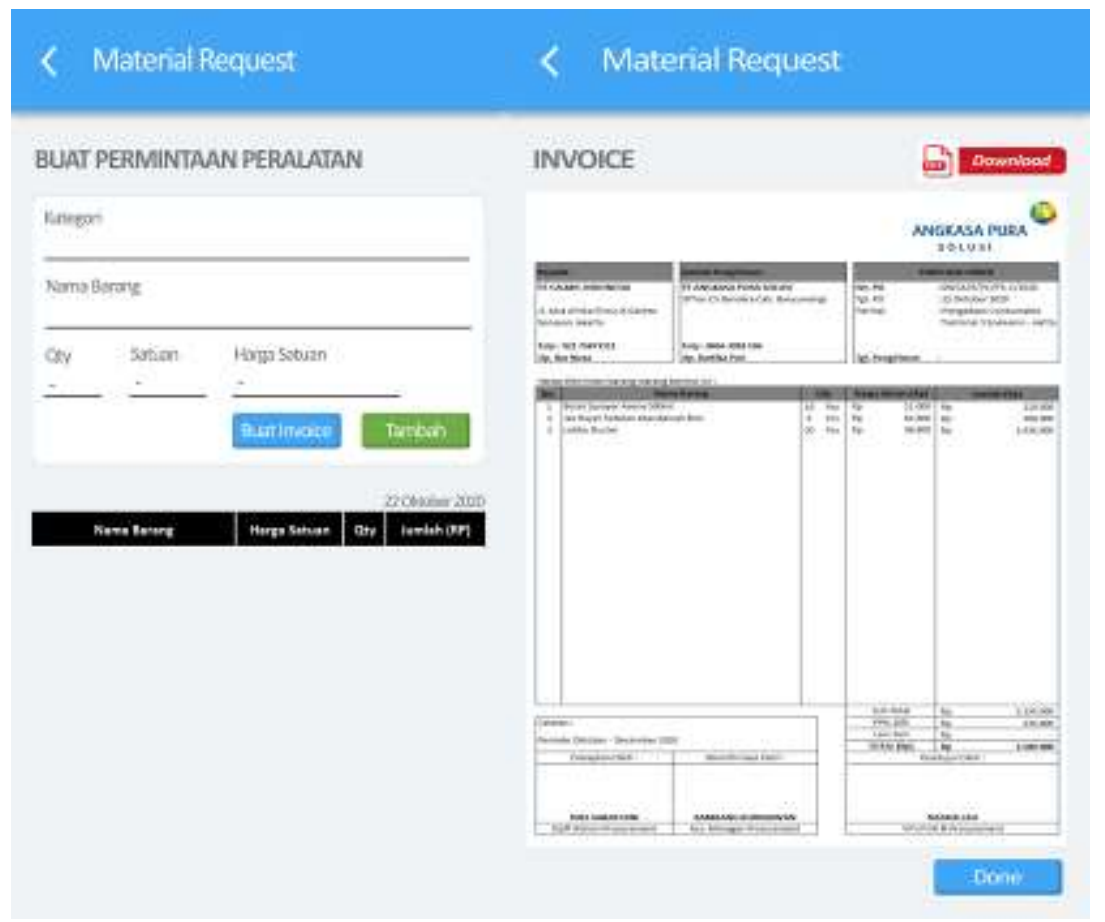

Gambar 4. Tampilan Menu Material Request

Tampilan menu material request pada Aplikasi SI-MaRCo yang merupakan tampilan untuk membuat pengajuan permintaan peralatan sesuai peralatan yang dibutuhkan. 


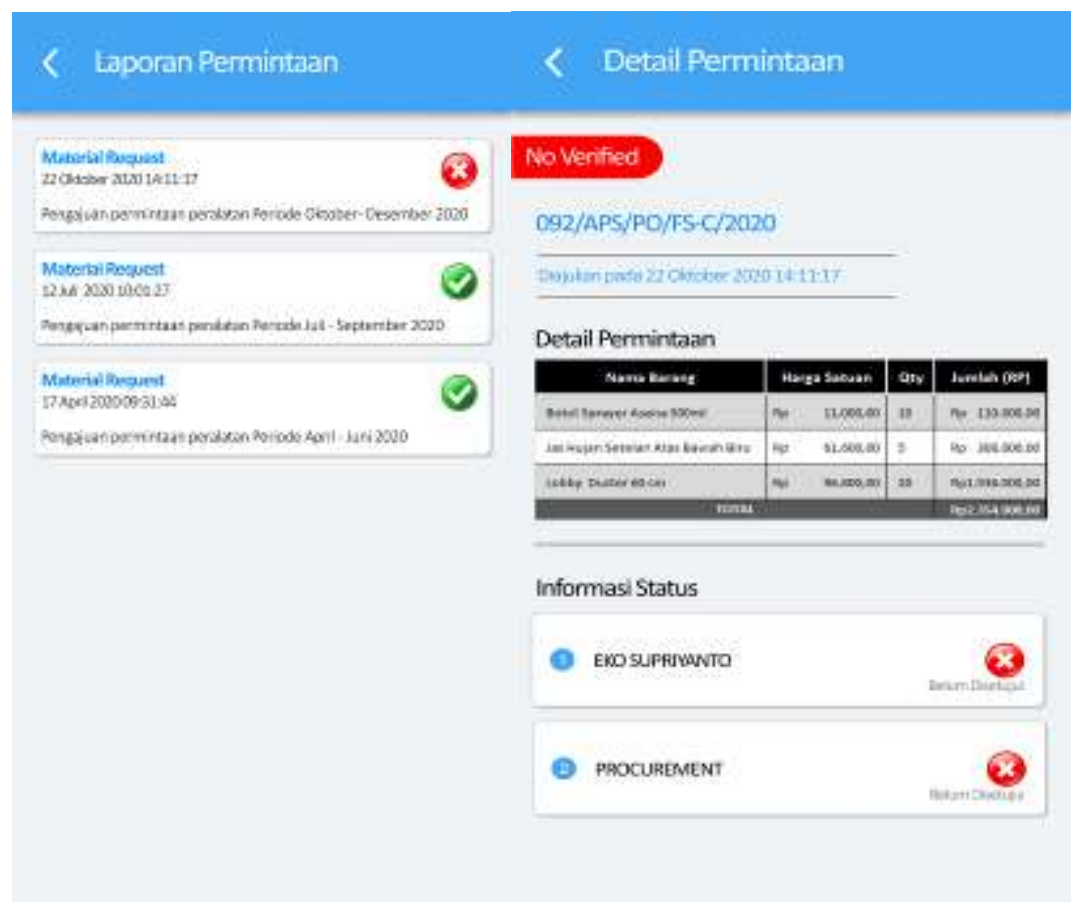

Gambar 5. Tampilan Laporan Permintaan Peralatan

Pada tampilan laporan permintaan menampilkan daftar permintaan peralatan yang sudah diajukan oleh admin atau PIC area, untuk memberikan informasi proses record permintaan peralatan sudah diajukan telah disetujui atau ditolak oleh manajer terkait.

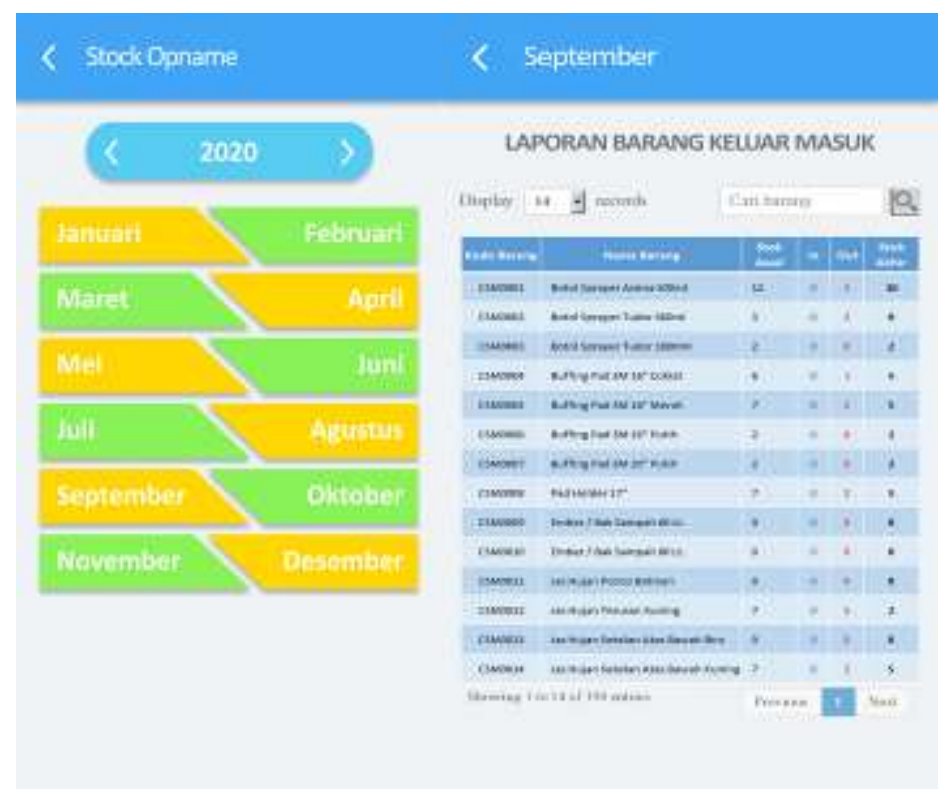

Gambar 6. Tampilan menu stok opname

Gambar 6 merupakan tampilan dari menu stok opname yang berisi laporan data pengeluaran dan pemasukan barang setiap bulannya yang tercatat melalui menu tambah, ambil dan masukan barang pada menu stok barang yang sudah diinput. 


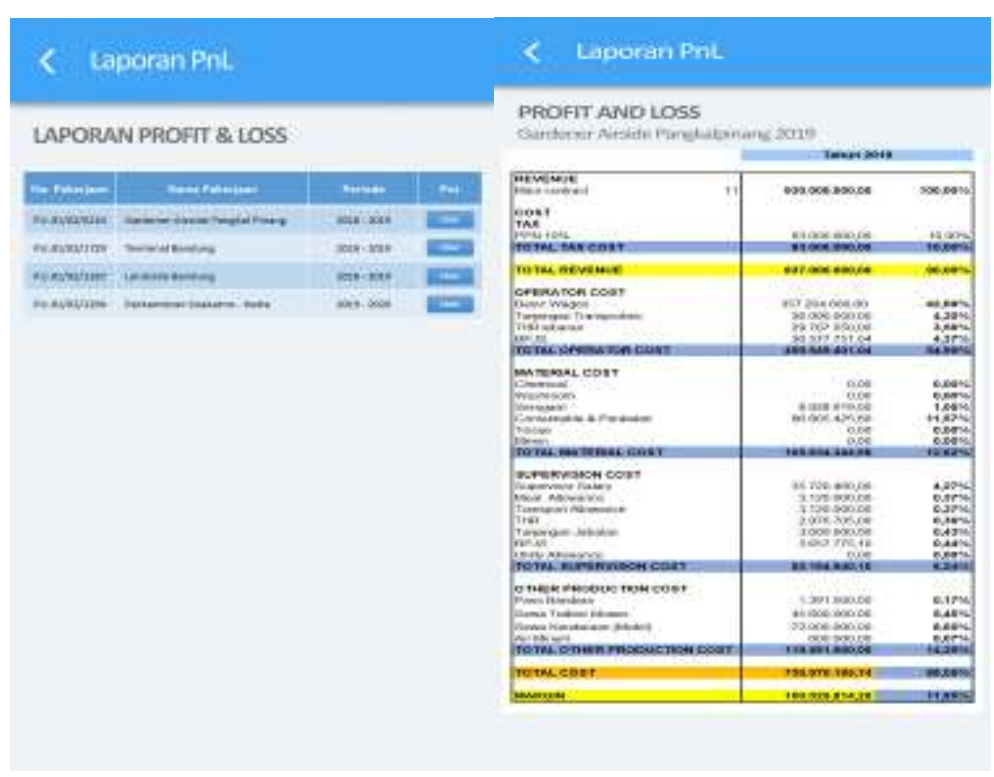

Gambar 7. Tampilan menu Profit \& Loss Report

Tampilan menu profit \& loss report menampilkan data laporan pendapatan dan pengeluaran biaya secara detail, sehingga cash flow dapat dapat terkontrol dengan mudah oleh admin ataupun PIC area sebagai acuan dalam membuat pengajuan permintaan peralatan. Agar biaya permintaan tidak melebihi pendapatan dari nilai kontrak yang didapat.

\section{KESIMPULAN}

Berdasarkan penelitian yang dilakukan pada sistem material pada PT. Angkasa Pura Solusi, maka terdapat beberapa kesimpulan sebagai berikut :

a) Proses pencatatan stok persediaan peralatan setiap peralatan yang masuk dan penggunaan peralatan keluar menjadi lebih efisien, efektif dan semua bentuk laporan terkait penggunaan peralatan kepada atasan menjadi lebih akurat dan mudah dikontrol.

b) Permintaan peralatan yang dibuat oleh admin maupun PIC area menjadi lebih mudah dan dapat diperiksa dengan mudah oleh staf Logistik Pusat, sehingga tidak menghambat permintaan peralatan yang dibutuhkan area.

c) Laporan profit and loss tidak lagi dibuat manual oleh Manajer serta dapat diketahui oleh staf Logistik Pusat dan seluruh PIC area. Sehingga mempermudah PIC area dalam memperhitungkan biaya permintaan peralatan agar tidak melebihi nilai kontrak yang didapat. 


\section{UCAPAN TERIMA KASIH}

Kami ucapkan terima kasih kepada stakeholder yang sudah memberikan kesempatna untuk melakukan penelitian serta kepada dosen pembimbing yang sudah memberikan arahan dalam penelitian ini. Tidak lupa mengucapkan terima kaish kepada semua pihak / orang yang telah mendukung baik dari pendanaan (indogiving.com) maupun semangat moril.

\section{DAFTAR PUSTAKA}

Sommerville, I. 2016. Pearson. Software Engineering, 10th ed.

Purnomo, D. 2017. "Model Prototyping Pada Pengembangan Sistem Informasi," J. Inform. Merdeka Pasuruan, vol. 2, no. 2, hal. 54-61.

Sanusi (2011:13)

Manurian, W., \& Dame, M. (2019, July). Perancangan Sistem Informasi Monitoring Permintaan Perlengkapan Peralatan Kantor Berbasis Web. In PROSIDING SEMINAR NASIONAL ENERGI \& TEKNOLOGI (SINERGI) (pp. 101-110).

Maimunah, M., \& Marina, C. Perancangan Sistem Informasi Monitoring Permintaan Perlengkapan Peralatan Kantor Berbasis Web pada PT Tirtanusa Indotama. Innovative Creative and Information Technology, 5(2), 167-180.

Syahrul, S., \& Mulyati, R. (2018). SISTEM INFORMASI PERSEDIAAN BARANG PERALATAN KANTOR PADA AMIK TRI DHARMA PEKANBARU. Jaringan Sistem Informasi Robotik-JSR, 2(1), 62-67.

Apriani, D., Aisyah, E. S., \& Anggraini, L. (2019). Rancang Bangun Sistem Informasi Inventory Peralatan Komputer Berbasis Website Pada PT Indonesia Toray Synthetics. Technomedia Journal, 4(1), 15-29.

Fridayanto, B. (2019). SISTEM INFORMASI SUPPLY CHAIN MANAGEMENT PERALATAN DAN PERLENGKAPAN PERTANIAN (Studi Kasus: PT Konco Tani) Supply Chain Management and Information Systems Of Agriculture Equipment (Case Study: PT Konco Tani) (Doctoral dissertation, Universitas Teknokrat Indonesia).

Fridayanto, B. (2019). Sistem Informasi Supply Chain Management Peralatan Dan Perlengkapan Pertanian. Skripsi.

Fuaddi, M. (2018). Pengembangan prototipe sistem informasi manajemen pemeliharaan peralatan medis berbasis Web-based prototype development of medical equipment maintenance management information system.

Munte, E. D. PERANCANGAN APLIKASI INVENTARIS ALAT-ALAT KANTOR DENGAN METODE PROTOTYPE STUDI KASUS: DINAS PENDIDIKAN KOTA SUBULUSSALAM Sariadin Siallagan.

Anwar, F. (2018). Aplikasi Stock Opname Peralatan PPSU Tingkat Kelurahan Berbasis Android (Doctoral Dissertation, Universitas Mercu Buana Jakarta). 